
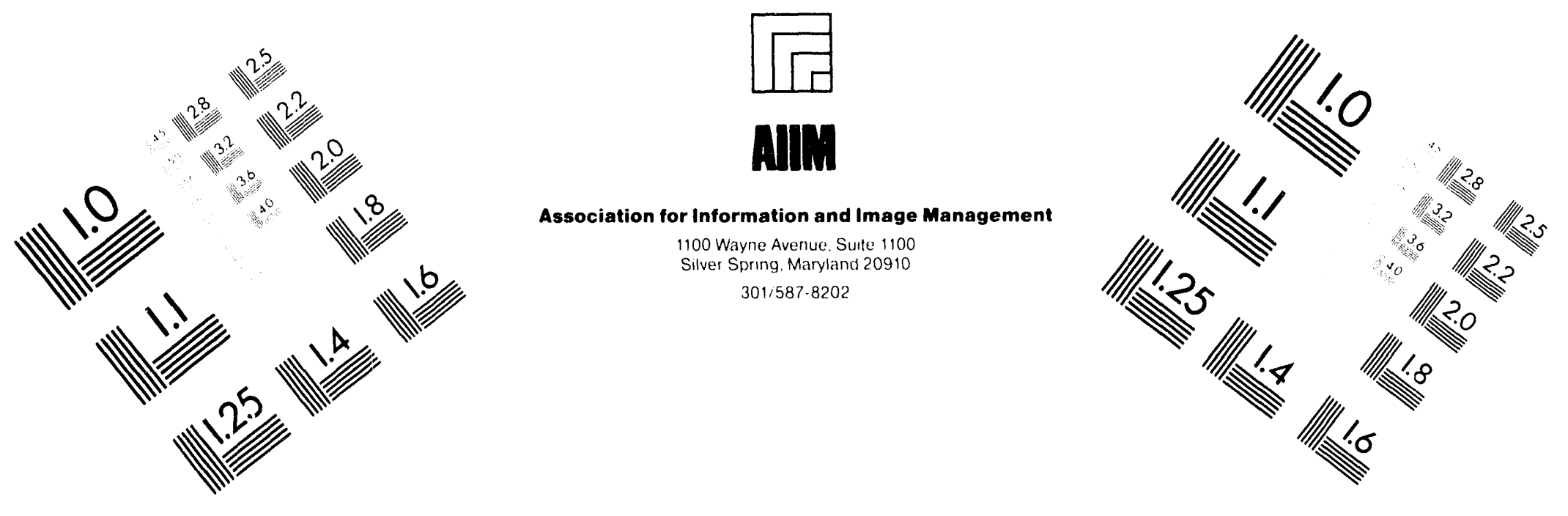

\title{
Centimeter
}

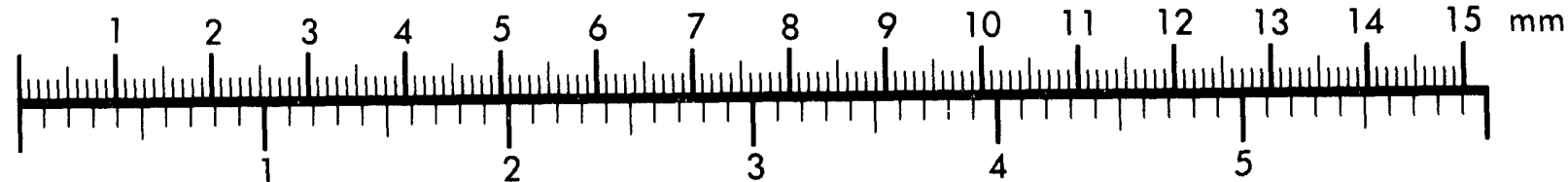

Inches
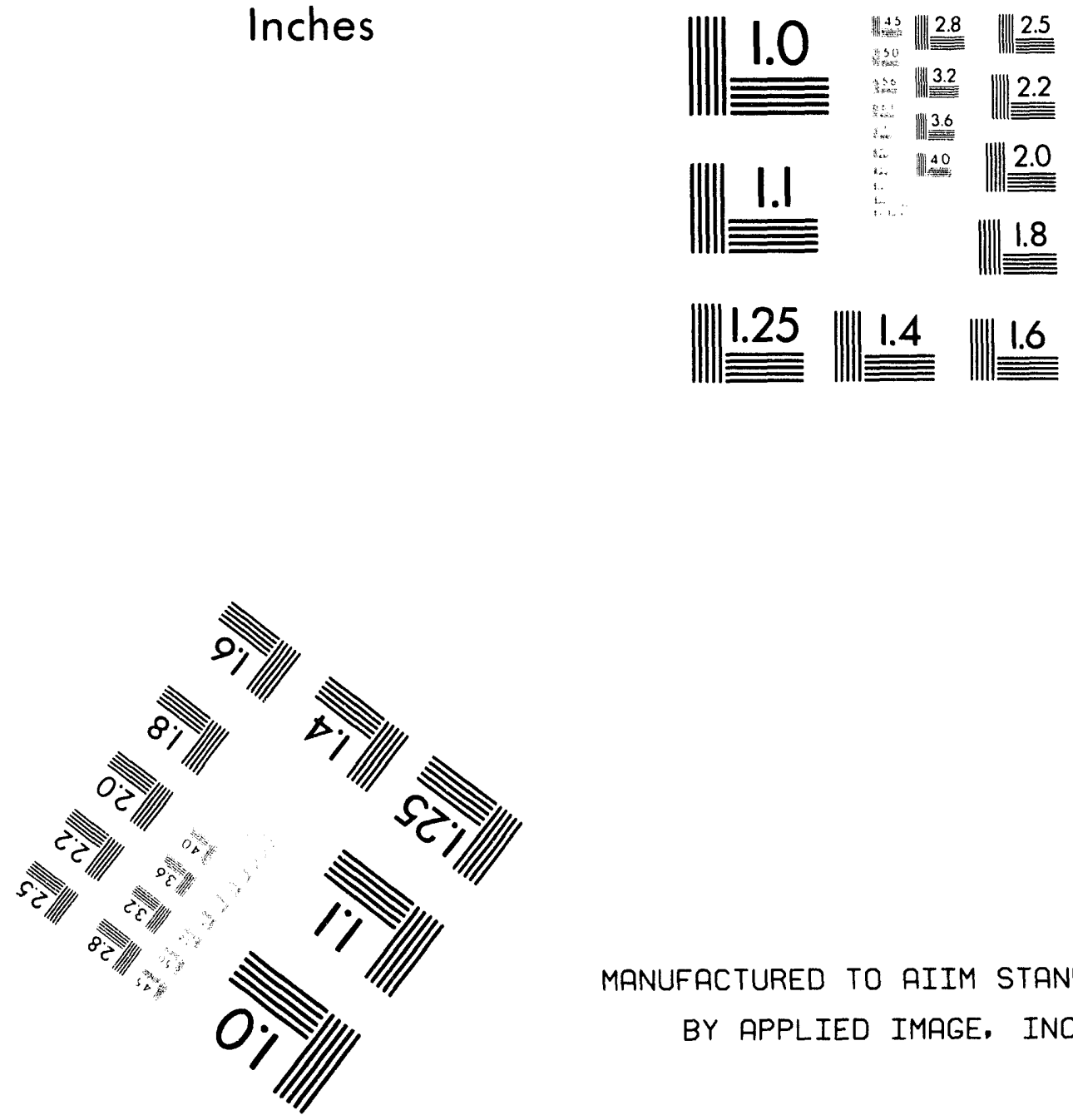

MANUFACTURED TO AIIM STANDARDS

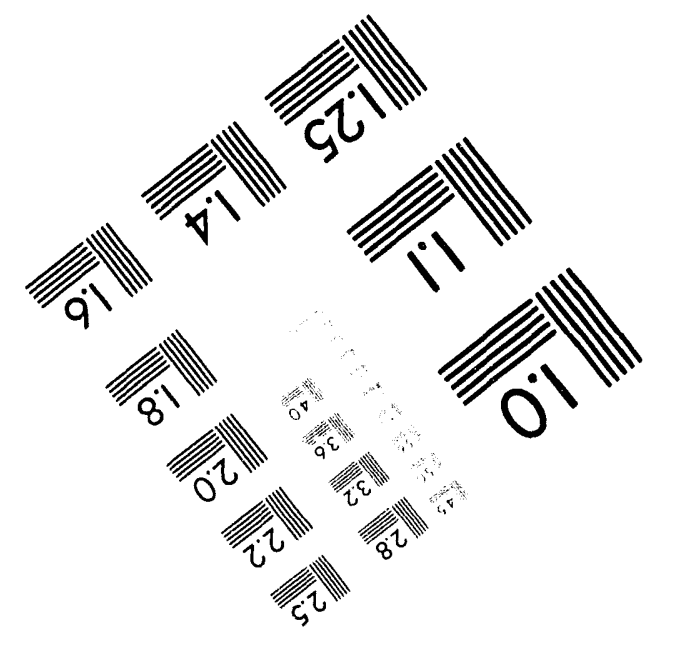



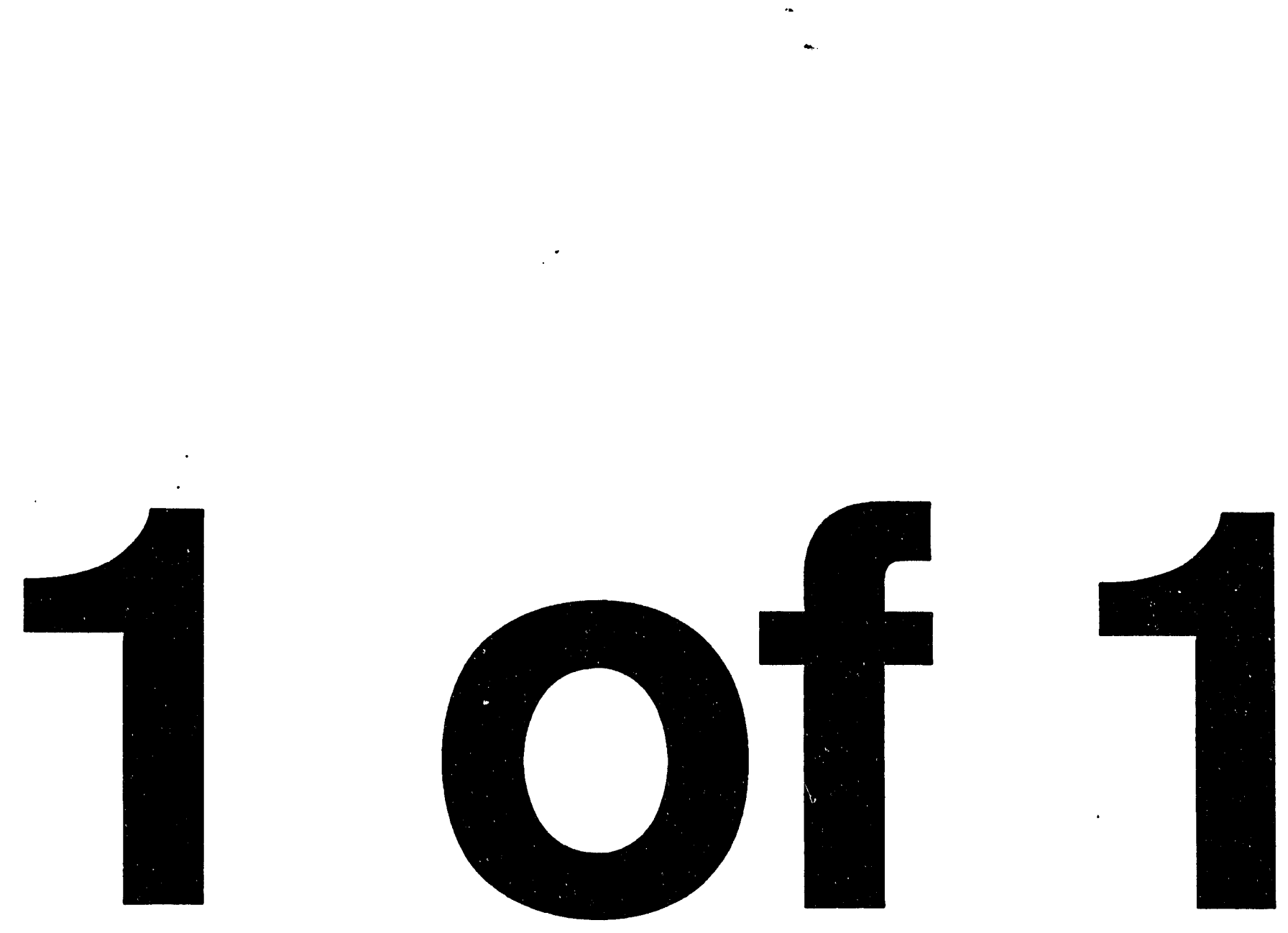


\section{Chemical Stockpile Disposal Program: Review and Comment on the Phase I Environmental Report for the Pueblo Depot Activity, Pueblo, Colorado}

by S.J. Olshansky, J.R. Krummel, A.J. Policastro, and L.D. McGinnis*

Environmental Assessment Division,

Argonne National Laboratory, 9700 South Cass Avenue, Argonne, Illinois 60439

March 1994

Work sponsored by United States Department of the Army, Office of the Assistant Secretary for Installations,

Logistics, and Environment

"McGinnis is affiliated with Argonne's Energy Systems Division. 


\section{CONTENTS}

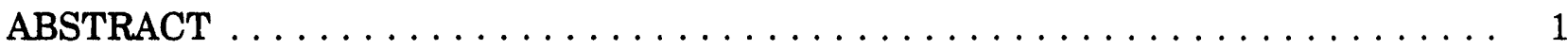

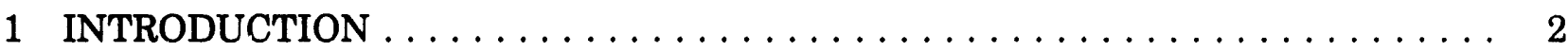

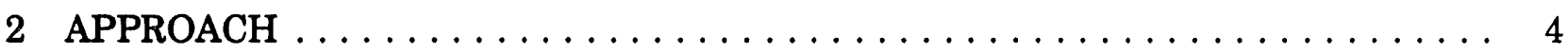

3 DATA APPLICABLE TO THE FPEIS DECISION $\ldots \ldots \ldots \ldots \ldots \ldots$

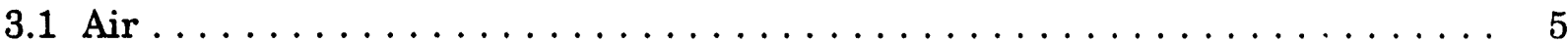

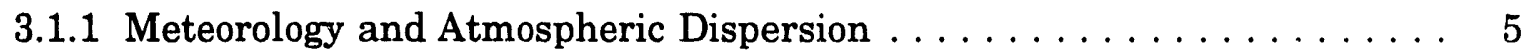

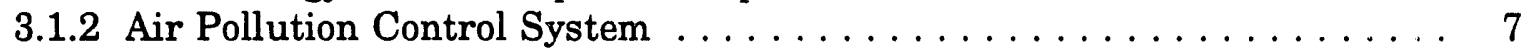

3.2 Population ............................... 9

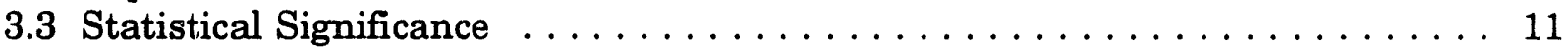

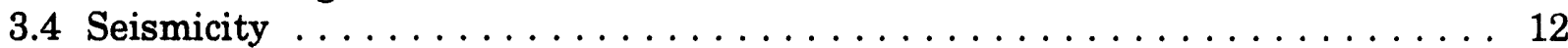

3.5 Emergency Planning and Preparedness . . . . . . . . . . . . 13

4 SITE-SPECIFIC EIS $\ldots \ldots \ldots \ldots \ldots \ldots \ldots \ldots \ldots \ldots \ldots \ldots \ldots$

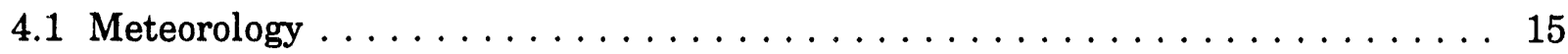

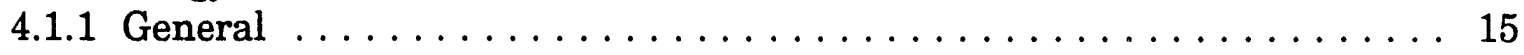

4.1.2 D2PC Model and Choice of Meteorological Conditions . . . . . . . 15

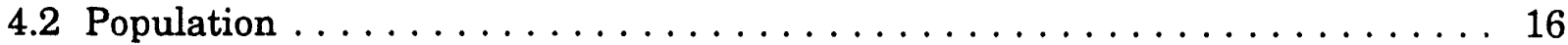

4.3 Social, Economic, and Cultural Resources $\ldots \ldots \ldots \ldots \ldots \ldots \ldots$

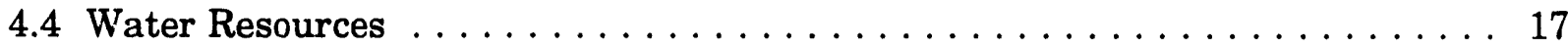

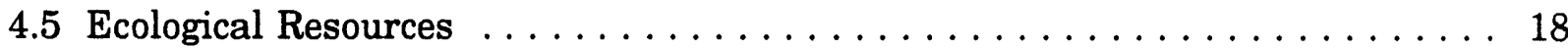

4.6 Emergency Planning and Preparedness . . . . . . . . . . . . . . . 19

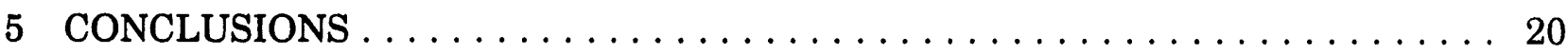

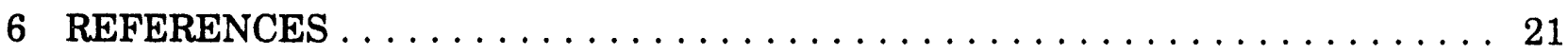

\section{FIGURE}

1 Phase I Concept and the Approach Used in this Review to Compare the FPEIS and Phase I Environmental Report 


\title{
CHEMICAL STOCKPILE DISPOSAL PROGRAM: REVIEW AND COMMENT ON THE PHASE I ENVIRONMENTAL REPORT FOR THE PUEBLO DEPOT ACTIVITY, PUEBLO, COLORADO
}

by

\author{
S.J. Olshansky, J.R. Krummel, A.J. Policastro, \\ and L.D. McGinnis
}

\begin{abstract}
As part of the Chemical Stockpile Disposal Program mandated by Public Law 99-145 (Department of Defense Authorization Act), an independent review is presented of the U.S. Army Phase I environmental report for the disposal of chemical agents and munitions stored at the Pueblo Depot Activity (PUDA) in Pueblo, Colorado. The Phase I report addresses new and additional concerns not incorporated in the final programmatic environmental impact statement (FPEIS). These concerns are addressed by examining site-specific data for the PUDA and by recommending the scope and content of a more detailed site-specific study. This independent review evaluates whether the new site-specific data presented in the Phase I report would alter the decision reached in the FPEIS that favors on-site disposal and whether the recommendations for the scope and content of the sitespecific study are adequate. On the basis of our review of the Phase I report, we concluded that on-site meteorological data from December 1988 to June 1992 appear to be of insufficient quality to have been used instead of the off-site Pueblo airport data. No additional meteorological data have been collected since June 1992. The Phase I report briefly mentions problems with the air pollution control system. These problems will likely require the systems to be upgraded at the Johnston Atoll site and at each of the other depots in the continental United States. Without such improvements, the probability of accidents during start-up and shutdown would likely increase. The Army has a lessons-learned program to incorporate improvements into the design of future facilities. The Phase I report does not make any design change commitments. These issues need to be fully evaluated and resolved before any final conclusion concerning the adequacy of the decision in the FPEIS can be made with respect to the PUDA. With the exception of this issue, the inclusion of other more detailed site-specific data in the Phase I report does not change the decision reached in the FPEIS (which favored on-site disposal at the PUDA). We recommend that site-specific data on water, ecological, socioeconomic, and cultural resources and emergency planning and preparedness be considered explicitly in the site-specific EIS decision-making process.
\end{abstract}




\section{INTRODUCTION}

The U.S. Army is implementing a strategy for compliance with Title 14, Part B, Section 1412, of Public Law 99-145 (Department of Defense Authorization Act), which requires destruction of all lethal unitary chemical agents and munitions. As part of this strategy, the U.S. Army developed a two-tiered approach for compliance with the National Environmental Policy Act of 1969 (NEPA). The first part of this approach involved the preparation of a final programmatic environmental impact statement (FPEIS) (U.S. Army 1988a) that compares alternative strategies on a national scale. The analysis considers disposal technologies and locations. The second part of the two-tiered approach is now in progress and involves the preparation of site-specific EISs to assess the effects at each location of the implementation of the disposal technology selected in the FPEIS, that is, on-site incineration.

Because of comments received during NEPA review of the FPEIS, the U.S. Army decided to conduct the site-specific NEPA impact analysis in two phases (U.S. Army 1988b). In Phase I, site-specific data relevant to on-site disposal were to be further reviewed and analyzed for each installation. In Phase II, the site-specific effects of constructing, operating, and decommissioning the incineration facility at each disposal location are to be considered.

The U.S. Army prepared the Phase I report for the Pueblo Depot Activity (PUDA), Pueblo, Colorado (U.S. Army 1993). The report contains information on human health and safety, environmental resources, and emergency response that is specific to the area around the PUDA. The stated objectives of the report are to determine (1) whether new data presented in the Phase I report would result in the rejection of on-site disposal at the PUDA as the environmentally preferred alternative (using the same methods and data-analysis tools as those used for the FPEIS) and (2) whether the new data indicate the presence of significant environmental resources that could be affected by the implementation of on-site disposal at the PUDA.

The U.S. Army decided that the Phase I report for the PUDA should be independently reviewed. This document presents the result of that review, which was conducted by research staff members at Argonne National Laboratory (ANL) for the U.S. Amy, Office of the Assistant Secretary, Installations, Logistics, and Environment. The Assistant Secretary requested that the reviewers determine the adequacy of the Phase I report, whether new data should be evaluated, and whether evaluation of new data would change the environmentally preferred alternative selected in the FPEIS. Previous reviews, also conducted by ANL staff, evaluated the Phase I environmental reports for the Tooele Army Depot (Krummel et al. 1988), the Anniston Army Depot (Krummel et al. 1989), the Umatilla Army Depot (Krummel et al. 1990a), and the Pine Bluff Arsenal (Krummel et al. 1990b).

Figure 1 shows the approach used to compare the sile-specific data and results presented in the FPEIS with the new information generated for the Phase I report. If the 


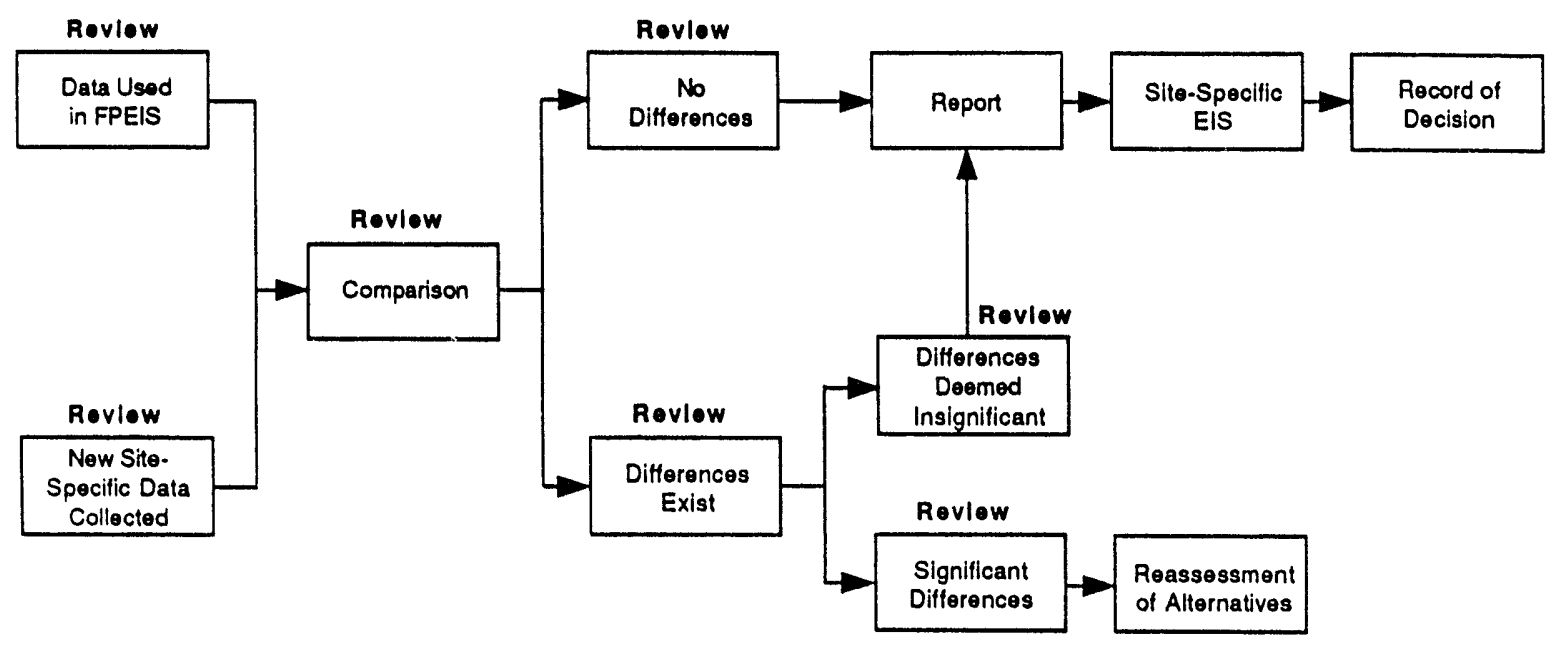

FIGURE 1 Phase I Concept and the Approach Used in this Review to Compare the FPEIS and Phase I Environmental Report (boxes labeled "Review" are germane to this review report) (Source: Adapted from U.S. Army 1988c)

data used in the Phase I report differ from those contained in the FPEIS, the differences are to be examined for significance. If significant differences are found, the selection of this specific disposal site as an alternative is to be reassessed. If the differences are found to be insignificant, this conclusion is to be reported in the site-specific EIS.

The Phase I environmental report contains site-specific data for an area within a $100-\mathrm{km}$ radius of the PUDA. Two types of data are presented: (1) data to support the decision analysis presented in the FPEIS (Figure 1) and (2) environmental resource data required for preparation of the site-specific EIS in Phase II. The Phase I report does not incorporate any new modeling analyses or probabilistic accident scenarios; those analyses and scenarios are carried through unchanged from the FPEIS. 


\section{APPROACH}

This review compares the site-specific data used in the FPEIS with the data presented in the Phase I report (Figure 1). Data were reviewed for completeness and adequacy to support modeling and computation of risk measures. This Phase I review explicitly follows the decision methodology developed in the FPEIS. Krummel et al. (1988, 1989) provide information on applying the FPEIS methodology to decisions of adequacy and completeness and describe the types of data explicitly considered by the methodology. Data adequacy applies to the Phase I information in terms of choosing the most appropriate parameters and variables in the modeling analyses, as well as incorporating all potential receptors in analyzing potential effects of on-site incineration of chemical agents at the PUDA. In this case, the receptors are the people located around the PUDA. The modeling analyses are dependent on the Phase I information for evaluating site-specific dose levels that could be experienced by the population around the PUDA. This review considers neither the U.S. Army Record of Decision (U.S. Army 1988d) nor the probabilistic accident analyses completed for the FPEIS to determine the chemical agent source terms.

This review also examines the information presented in the Phase I report that will be used for the Phase II site-specific EIS. Specifically, this review addresses the adequacy of the data to support a site-specific impact analysis. Although these data were not used in the FPEIS decision process, the information will be used both to define baseline enviroumental conditions at the PUDA and to conduct impact analyses for the site-specific EIS. In addition, recommendations are provided, where appropriate, on the types of information and analyses that should be included in the site-specific EIS.

Section 3 of this review examines the data explicitly used in the FPEIS methodology to make decisions related to disposal options. These data areas include meteorology, population, seismicity, and emergency planning. Section 4 of this review examines data that will be used in the site-specific EIS but that were not explicitly included in the FPEIS decision methodology. These data areas include water, ecological, social, economic, and cultural resources. Section 4 also contains recommendations for site-specific data and analysis requirements for meteorology, population, and emergency planning. 


\section{DATA APPLICABLE TO THE FPEIS DECISION}

\subsection{AIR}

\subsubsection{Meteorology and Atmospheric Dispersion}

The PUDA site is situated on gently rolling terrain. Two ravines occur in the vicinity of the incineration site. One is on the west side of the PUDA, and the other is east of Thatcher Ranch (the nearest residence to the incineration site). An item of meteorological interest is that the PUDA site is located in the Arkansas River drainage in the lee of the Rocky Mountains. Katabatic flows out of the Arkansas River watershed and Chinook winds are expected in the area. Average summer mixing heights vary from $350 \mathrm{~m}$ in the morning to $3,600 \mathrm{~m}$ in the afternoon (Williams et al. 1987). Wind speeds are low during inversion conditions, and the flow is very localized.

The PUDA risk assessments require the use of dispersion modeling predictions. The D2PC model was used for the two sets of meteorological scenarios developed in the IPEIS - conservative-most-likely and worst-case. Conservative-most-likely conditions were chosen as Class D atmospheric stability and $3 \mathrm{~m} / \mathrm{s}$ wind speed (denoted by the designation $\mathrm{D}, 3)$; worst-case conditions were selected to be Class $\mathrm{E}$ stability and $1 \mathrm{~m} / \mathrm{s}$ winds $(\mathrm{E}, 1)$. The D,3 scenario assumes a frequently occurring meteorological condition that would result (in the event of an agent release) in relatively large mustard gas doses as compared with other frequently occurring conditions. The E,1 scenario is intended to represent a credible condition that results in near-maximum doses in the event of an agent release. Predictions based on these two meteorological scenarios were used to estimate how the population would be affected by the five measures of risk used in the FPEIS (U.S. Army 1993).

In addition to the meteorological tower at the Pueblo airport, there is a $10-\mathrm{m}$ meteorological tower that has been in operation since December 4,1988 , at a location about 5.6-6.0 $\mathrm{km}$ west of the proposed incineration site. Data collected at the 10-m meteorological tower should be more representative of the meteorology of the incineration site (because of its location) than the data from the Pueblo Memorial Airport (located about $16 \mathrm{~km}$ from the site) that were used in the Phase I report. For instance, the airport site is closer to the Rocky Mountains and is likely to be influenced to a greater degree by the drainage flows from the mountains. The frequency of Class $\mathrm{E}$ and $\mathrm{F}$ stabilities may be significantly different between the two sites.

In the Phase I report, the analysis of data from December 1988 through June 1992 revealed problems with data quality. The Phase I report is based on analyses using selected time periods between December 1988 and June 1992. The data revealed several problems with the instrumentation, such as fictitiously slow wind speeds, the lack of instrument calibration, sluggish wind instruments, and the wind vane being stuck in the north direction. Evidence provided in the Phase I report on the quality of data for this time period is 
sufficiently convincing to consider eliminating those data from consideration for determining long-term statistical averages of winds and stability classes at PUDA.

No additional meteorological data were acquired at the on-site station after June 1992 because the tower had been placed there to support the destruction of the Pershing rocket motors associated with the Intermediate-Nuclear Force Treaty. That destruction effort ended in approximately June 1991, and the last meteorological data collection was completed about 4-6 months following that destruction period (Steranka 1993).

It is to be expected that the wind direction at the site would be different from that measured at Pueblo Memorial Airport because the stations are at different distances from the nearby mountains, thereby producing different drainage flow patterns. In fact, it is likely that the winds at either of these sites would not change direction once the plume has traveled 20 kilometers. If good quality data were available from both the on-site station and the airport station, then a realistic plume simulation would be accomplished by using data on wind patterns obtained both at the tower at the PUDA and the airport. A wind field model that uses both sets of hourly data would have a much greater chance of estimating the correct directional changes of an accident plume that may leave the PUDA site.

The most critical scenario for evaluation would likely be a major release during a summer evening or night when ambient temperatures have cooled, yet remain above the vaporization temperature for mustard gas (i.e., $59^{\circ} \mathrm{F}$ ). Presence of a very low inversion height at the time of a nighttime accident (when incineration would take place) could create a plume that passes off-site with a meandering path toward Pueblo. This condition of Class $\mathrm{F}$ stability at nighttime during a release and its concomitant long residence times and meandering plume motion were not considered in the Phase I report. The use of the straightline Gaussian approach of the D2PC model does not account for the likely change in direction of the flow as a function of distance and terrain differences.

For the Phase I report, the "maximum number of fatalities" associated with a particular downwind direction was computed by rotating the predicted D2PC plume in increments of one compass degree around the point of release. Fatalities were then computed for each of these increments. The absolute largest number of fatalities among the 360 computations was identified in the FPEIS as the maximum number of fatalities associated with that particular downwind no-deaths distance category. In each of these 360 computations, the plume was assumed to travel in a straight-line path in the direction of a different degree of the compass. However, looking at the worst-case of the 360 computations does not necessarily provide a conservative prediction of fatalities. Because of differences in terrain and the change of wind direction with time, plumes do not travel in a straight line. The wind tends to blow in one direction for a few minutes and then turn to a different direction a few minutes later. Numerous changes in the direction of a plume can occur over long distances. The likely possibility in the PUDA case is that the plume would change direction as it heads downwind, possibly affecting more people than predicted by a straight-line dispersion simulation. Depending on the exact distribution of the population, a strategically located zigzag plume could cause more fatalities than predicted by any of the 
360 straight-line plume computations. The Phase I document does not consider that possibility. In fact, no flow and dispersion experiments have been done at the site to understand the flows during the important nighttime meteorological conditions.

Within the framework of the U.S. Army methodology presented in the FPEIS, the conservative-most-likely and worst-case combinations of wind speed and stability class had to be selected on the basis of straight-line Gaussian theory and the meteorological data given in the Phase I report. After examining the meteorological data presented in the Phase I report, the U.S. Army selected for analysis the stability/wind speed condition of D,3 for the conservative-most-likely scenario and E,1 for the worst-case scenario. These choices were identical to those in the FPEIS, and the measures of risk did not need to be recalculated because of changes in meteorology. However, the choice of D,3 and E,1 conditions for analysis was subjective, and other stability/wind speed combinations are both possible and defensible. All reasonable stability class/wind speed combinations (in addition to D,3; E,1; and D,1 tested) should have been tested to determine which would lead to the greatest impacts. For example, a choice of $\mathrm{D}, 4$ would lead to a more diluted plume than $\mathrm{D}, 3$, but the plume would cover more area and possibly affect more people. Recommendations concerning this matter are discussed in Section 4.1.2.

\subsubsection{Air Pollution Control System}

The Phase I document discusses recent experiences at Johnston Atoll Chemical Disposal System (JACADS). It also provides a brief discussion of the experience of the pollution abatement system at JACADS. That discussion generally reviewed the positive features of the system, including its ability to meet emissions standards. For instance, a National Research Council (NRC) report was quoted as having stated that "JACADS emissions data from the Toxic Substances Act (TSCA) R\&D test burns for the deactivation furnace system and the Resource Conservation and Recovery Act (RCRA) trial burns for the liquid incinerator indicate excellent system performance..." (National Academy of Sciences 1992). Specifically, the liquid incinerator destroyed agent to below the detection limit in the discharge stack. That detection limit corresponded to approximately $25 \%$ of the limit for stack emissions that would endanger the health of workers or the general public. Other emissions were well-controlled.

On the other hand, the deficiencies with the system were not detailed other than to say that the pollution abatement systems at JACADS have experienced plugging of the demister candles to an extent greater than expected. A more detailed description of the NRC findings is provided in the National Academy of Sciences (NAS) (of the National Research Council) workshop and letter reports (National Academy of Sciences 1991, 1992). It should be kept in mind that the workshop report represents opinions of experts relating to the air pollution control system at JACADS but does not represent the official position of the National Research Council. The letter report, on the other hand, presents specific recommendations to the U.S. Army made by the National Research Council (National Academy of Sciences 1992). The workshop and letter reports indicate that the air pollution control systems at JACADS (the same systems that are planned for the eight depots) are not 
state-of-the-art (as of 1992) and have operational problems largely because of the presence of sodium salts in the exit of the liquid incinerator. The frequent downtimes of the incinerator increase the probability of an accident during shutdown and start-up periods. This increased probability of accidents was not considered in the risk assessment performed in the programmatic EIS or in the Phase I report. It is possible (with the current set-up of the air pollution control system) that the unburned agent can escape the air pollution control system during a start-up or shutdown accident. The letter report recommends that improvements be made to the design of the air pollution control systems for the eight depots on the basis of developments enhancing the state of the art since the design of the JACADS facility many years ago. Essentially, the Army needs to make changes in the type of system used at JACADS before it is used at the PUDA. The NAS letter report indicates that the JACADS air pollution control system is operating safely but is not operating as reliably as it could be. The letter report does not recommend that the air pollution control system at JACADS itself be changed, but recommends changes to the design for later use at the eight depots. According to the workshop report (National Academy of Sciences 1991):

The candle demisters at JACADS are plugging at an unacceptably high rate due to insoluble particles in the gases being cleaned. . . . While the candle demisters are achieving acceptable particulate loadings in the stack gases, when they operate, they should be replaced with a technology that is more tolerant of insoluble particles or augmented to reduce the rate of plugging.

The workshop report suggests that alternatives may exist for the Army, including a front-end spray drier with a baghouse. Resolution of this problem should, of course, be based on a more detailed study of this issue by the Army. A detailed study by the Army should lead to solutions that would reduce the many unanticipated shutdowns of the system, thereby reducing the probability of an accident to the levels assumed in the FPEIS and the Phase I report.

A second concern is revealed by the following two quotes from the workshop report (National Academy of Sciences 1991):

While the present incineration and pollution control system is capable of meeting current and probably future requirements, it is likely to develop excessive pressure drops when operating continuously, forcing plant shutdowns. The ability to deal with power failure, upsets, and other transients should be improved.

The potential for puffs when excessive agent is placed in the rotary kiln requires attention. The ability of the present afterburner and pollution abatement system to suppress emissions during such puffs is uncertain. 
One alternative suggestion for consideration by the Army (made in the workshop report [National Academy of Sciences 19911) is the installation of a back-end control device aimed at avoiding the accidental release of unburned agent during a shutdown or start-up:

Use of an activated carbon filter downstream of the scrubbers would remove pulses of agent and low-level organics. It would offer an available technology for dealing with these problems and the resulting alarms. The ability to reduce mercury vapor and dioxin emissions is an additional feature of carbon.

The letter report (National Academy of Sciences 1992) suggests that:

The Army should consider incorporating passive controls, such as activated charcoal beds, to ensure the lowest emissions even under temporary upsets (e.g., puffs) that might not be controlled by the existing afterburner.

An accidental relea ie during shutdown may be more of a concern than during start-up because of the greater likelihood that other equipment may fail during an emergency shutdown. No statements are made in the Phase I report about these problems and the solutions (if any) that the Army has committed to making. Without responses to the NAS workshop comments and commitments to meet official recommendations, it is of concern that the prubability for accidental releases is increased over that assumed in the Phase I and FPEIS documents.

The Army is aware of the above findings of the NAS letter report and workshop report and has developed a "lessons-learned" program. This program is aimed at reviewing the operation of the pollution abatement system at JACADS in order to incorporate improvements into the design for the future continental United States (CONUS) facilities. The Phase I report contained no discussion of commitments concerning improvements to the JACADS pollution abatement system for PUDA.

\subsection{POPULATION}

In the FPEIS, the size of the residential (off-base) population near the PUDA was based on 1980 U.S. census data. In the Phase I report, 1986 population estimates from the Census Bureau were used. Data from the 1990 census were not used in the Phase I analysis because they were not available at the time of the study. The methods used to distribute the population in the FPEIS and in the Phase I report have been discussed and critiqued in previous reviews (Krummel et al. 1988, 1989). The data and methods used to identify the size and distribution of the off-base population in the affected area and the new assumptions used in the Phase I report for redistributing the population were both valid and appropriate.

On the basis of updated population counts provided by the Census Bureau and the exclusion of residents from areas that are known to be nonresidential (e.g., within the PUDA 
boundary and the Arkansas River), the Phase I report states that 10,185 more people are located in the potentially impacted zone near the PUDA than was estimated in the FPEIS. The revised population estimates resulted in increases in the number of people living $50-100 \mathrm{~km}(+2,508), 35-50 \mathrm{~km}(+54)$, and $20-35 \mathrm{~km}(+8,634)$ from the proposed disposal facility. Reductions in the estimated population occurred at distances of $1-2 \mathrm{~km} \mathrm{(-6),2-5 \textrm {km }}$ $(-43), 5-10 \mathrm{~km}(-1)$, and $10-20 \mathrm{~km}$. (-961) from the facility.

When these new population values were translated into revised fatality estimates, it was determined that $\mathbf{3 0 0}$ more deaths would occur under potential maximum worst-case meteorological conditions than was estimated in the FPEIS. Within specified distances from the site, fatalities would be greater at a distance of $10-20 \mathrm{~km}(+1)$ and $20-50 \mathrm{~km}(+720)$. A reduction in the number of fatalities was estimated to occur at distances of 5-10 km (-1) and 50-100 km (-420). It should be emphasized, however, that the only differences between the Phase I repnrt and the FPEIS with respect to these calculations were the changes in population size and distribution. For example, Tables 6.2 and 6.3 of the Phase I report show that the estimated population increased in the Phase I analysis at almost all of the distances and wind directions relative to that estimated in the FPEIS. As a result, it is inconsistent to find a reduction in estimated fatalities of 420 people under worst-case meteorological conditions within $50-100 \mathrm{~km}$ of the site, when the total population at risk actually increased by 2,508 , and the population in every wind direction from the site increased (with the exception of minor decreases in the south and east-northeast directions).

On the basis of the ranges of risk provided in Figure 6.i of the Phase I report (U.S. Army 1993, p. 6-14), the revised fatality estimates result in a one-shade increase in the probability of one or more fatalities with continued storage and no change in the shading patterns for the on-site disposal and national disposal alternatives. In the Phase I report it was stated that "as a result of fewer people living close to the PUDA installation boundary [by comparison to estimates made in the FPEIS], small accidental releases of chemical agent ... now produce no fatalities" (p. 6-15). This difference is not based on an observed change in the actual distribution of people near the proposed disposal site. The difference is attributable to the use of the actual PUDA boundaries in the Phase I report in place of the generic boundaries of $500 \mathrm{~m}$ that were used in the FPEIS. That is, people that were distributed to areas between $500 \mathrm{~m}$ and $2 \mathrm{~km}$ from the proposed disposal area in the FPEIS were redistributed in the Phase I report to areas beyond $2 \mathrm{~km}$. The closest resident is acknowledged to live $2.8 \mathrm{~km}$ from the site of the proposed disposal facility. The redistribution assumption used in the Phase I report is valid and appropriate.

To achieve a significant difference in risk (using the U.S. Army's definition of significant) in terms of maximum number of fatalities under worst-case conditions, the number of deaths would have to increase from 16,500 as estimated in the FPEIS to some larger number. This number cannot be determined from the pictogram provided in Figure 6.1 of the Phase I report. Nevertheless, the probability that the estimated number of fatalities could increase to levels that would be significant by using the U.S. Army's definition are extremely remote, as noted by Krummel et al. (1989, p. 10). The only demographic conditions under which differences of the magnitude required to produce a significant difference would 
occur are (1) with the recalculation of risk using on-site and special populations in the fatality estimates and (2) under conditions where extremely large increases in population occur rapidly within very narrow and short distances from the site.

\subsection{STATISTICAL SIGNIFICANCE}

Alternatives considered at each tier of analysis were accepted or rejected on the basis of a determination of the relative significance of measures of risk. A pictogram was used to portray the numerical probabilities of various events occurring, and four different shadings were used to identify four ranges of risk. The Phase I report (U.S. Army 1993) notes that the measures of risk might be in error by as much as a factor of 10 in either direction, but this estimated error was not computed mathematically because "the maximum number of fatalities did not depend on accident probabilities or frequencies and therefore had no expressed uncertainty" (p. A-7). It was also stated that statistical significance was operationally defined throughout the analysis as a two-order-of-magnitude difference in risk, where the orders of magnitude were defined by the ranges of risk presented in the pictogram. That is, for two measures of risk to be considered as having different statistical significances, it was required that there be a minimum 100-fold difference in risk. This concept of statistical significance and the ranges of risk presented in the pictogram were not based on statistics but, instead, were chosen on the basis of a subjective interpretation of what the authors of the Phase I report considered to be a conservative estimate of risk. That is, a 10 -fold range of error and 100 -fold difference in risk were considered by the authors to be conservative.

The three-tiered approach that was presented in the Phase I report (U.S. Army 1993, Figure 2.1, p. 2-2) implies that decisions to accept or reject differences among alternatives were based on statistical comparisons of relative risk. The comparison of programmatic alternatives under Tier 1 (human health impacts) was made with a subjective rather than statistical interpretation of statistical significance. Ecosystem and environmental impacts considered in Tier 2 of the comparison of alternatives were never quantified and, therefore, could not have been accepted or rejected on the basis of statistical analyses. Nevertheless, it was stated that regional and on-site disposal alternatives were considered indistinguishable in light of ecosystem and environmental impacts (p. 2-5).

In the third tier (emergency planning and preparedness effects), measures of risk were not deemtd necessary for the Phase I analysis (U.S. Army 1993, p. 2-3). It was stated, however, that regional disposal was rejected because of the greater difficulties in providing adequate emergency response along transportation corridors as compared to the region around each depot, thus allowing on-site disposal to survive the three tiers of analysis to become the preferred alternative (p. 2-5). Furthermore, the Phase I report states that no proven or acceptable method exists to quantify the potential for reduction in impacts associated with emergency planning and preparedness (p. A-7) and that "because the Army will implement enhanced emergency planning and preparedness at the installation regardless of the alternative selected, the benefits or risk reductions attributable to emergency planning and preparedness ... should not affect site preference and have not been considered" 
(U.S. Army 1993, p. A-15). It is difficult to justify on-site disposal surviving the third tier of analysis when risk measures for the variable of interest (emergency planning and preparedness) admittedly cannot be quantified and were not deemed necessary for the Phase I analysic.

Finally, the Phase I report states that "if there were consistent differences in the measures of risk between alternatives (even at one order of magnitude of difference in the pictograms), this consistent difference is an indication that significant differences between alternatives may exist from an overall perspective. However, such consistent differences were never used in the selection method [emphasis ours] to either select or reject an alternative" (U.S. Army 1993, p. A-7). To reduce confusion, it is suggested that any reference to a strengthening of the validity of conclusions based on consistent (but not significant and never used) measures of risk be eliminated from the discussion (U.S. Army 1993, p. A-14).

\subsection{SEISMICITY}

The greatest potential for on-site surface rupture is from the Fowler Fault, a $20-\mathrm{km}$ long "capable fault" located about $18 \mathrm{~km}$ southeast of the site with $18 \mathrm{~m}$ of dip-slip displacement - a fault that would strike in a northwesterly direction. An earthquake of body wave magnitude 5.7 on the Fowler Fault is selected as the one that would generate the estimated peak ground acceleration (EPGA) at the site. An 18-m fault scarp displacing Pleistocene stream deposits is noted (U.S. Army 1993), although overlying Holocene stream deposits are not known to be displaced, thus bracketing the fault in time between $3,000,000$ and 10,000 years before present. Orientation of the fault is parallel with the edge of the Denver Basin. The Phase I report states that a hypothetical projection of the fault strike to the northwest, within the bounds of uncertainty, would pass beneath PUDA.

A site-specific seismic risk analysis has not been performed for the PUDA, and there are no data available for nearby sites that may be used as surrogates (U.S. Army 1993). In addition, most of the important structures at the PUDA are cloned after facilities built at the Tooele Army Depot in Tooele, Utah. This means that facilities at the PUDA were designed with 1985 Uniform Building Code (UBC) standards for seismic zone 3 even though the PUDA is in seismic zone 1. Thus, the earthquake-resistant design at the PUDA may be considered conservative only if the regional risk analyses for seismic zone 3 also apply to seismic zone 1 . Although no surface faulting has been detected at the PUDA, the lack of site-specific earthquake risk analysis renders speculative any opinions regarding ground acceleration probabilities and surface rupture. Because of the spatial and temporal characteristics of the Fowler Fault and the lack of specificity relative to seismic risk analysis at the PUDA, it is questionable whether earthquake hazards at the site may be considered conservative as claimed by the Army (U.S. Army 1993, p. 6-6). 


\subsection{EMERGENCY PLANNING AND PREPAREDNESS}

In the FPEIS and the Phase I report, the risk reductions associated with emergency planning and preparedness used to support the decision for on-site disposal were not measured and compared with off-site transportation risks (U.S. Army 1993). Therefore, no quantifiable basis exists for determining whether the site-specific information on emergency planning and preparedness contained in the Phase I report is sufficiently different from that considered in the FPEIS to alter the decision in favor of on-site disposal.

It should be emphasized that a large database exists on the Army's record of transporting chemical munitions for the past 50 years. In the history of chemical munitions in the United States, there has never been a chemical agent fatality associated with the movement of these munitions, nor have there ever been reported incidents or injuries resulting from these chemical agents during their transport (U.S. Army 1993, p. 4 1). This perfect record of safe transport of chemical munitions was maintained during the recent movement of munitions from Europe to Johnston Island. Consequently, it is not possible to determine the effectiveness of emergency planning and preparedness in reducing or eliminating fatalities from the accidental release of agent during its transport. However, it is acknowledged that "it would have been unlikely that casualties could have been avoided in the event of an accidental chemical agent release [during] . . rail movement of unitary chemical weapons in Europe... even with the development and implementation of [extensive] emergency response capabilities" (U.S. Army 1993, p. 7-10).

Several differences in the actual rail movement in Germany and the proposed rail movement of the PUDA stockpile were also noted as reasons why the German experience cannot be applied to the PUDA. For example, although the distance travelled by the German and PUDA stockpiles is roughly the same (about $997 \mathrm{~km}$ ), it was argued that the European rail route passed through six states - each with its own disaster control force $\rightarrow$. while the PUDA stockpile would move through only two U.S. states, Colorado and Utah. The rationale provided for noncomparability on this issue was that states in the United States are empowered with more legal authority to control their borders than German states. However, we conclude that the legal authority of states to control their borders has no bearing on the accident and health risks associated with the transport of the PUDA stockpile.

A second difference noted was that the sizes of the inventories at the German and PUDA stockpiles are different. The PUDA stockpile is estimated to be about seven times the size of the stockpile that was in Germany. It took 10 days to transport all of the German munitions the $997 \mathrm{~km}$ to the point of transfer to the cargo vessels, and it is estimated that it would take 49 days to transport the PUDA stockpile to Tooele. There were over 96 million munition-kilometers of incident-free rail transport of the German munitions, and no evidence was provided to indicate that the rail transport of the PUDA stockpile would be a higher risk than that experienced by the transport of the German stockpile.

A third difference noted was that the populations at risk for the two moves are quite different. The population data for the movement of the German stockpile indicate that the population density along the transportation corridor ranged from 151 to 1,618 persons $/ \mathrm{km}^{2}$. 
The maximum population density along the transportation corridor for the PUDA stockpile to Tooele, Utah, would be only 12.5 persons $/ \mathrm{km}^{2}$. The transportation route for the PUDA stockpile passes through much less densely populated areas than that already traversed by the German stockpile; the implication is that the transport of munitions in the United States would be safer than that experienced in Europe.

A final difference noted was that the hazards presented by the stockpiles are different. The German stockpiles contained nerve agents GB and VX, while the PUDA stockpile contains only mustard agent. Although different protective action strategies and emergency response capabilities may be needed when transporting these various agents, there is no evidence to indicate that it would be any more difficult or risky to transport mustard gas than it would be to transport GB or VX. Furthermore, it was stated in the Phase I report that "the effectiveness of emergency response for persons close to the accident site would likely be minimal, since the lethal plume may arrive before sufficient response capabilities could be mobilized and deployed. This would particularly be the case if the accident occurred in a densely populated area" (U.S. Army 1993, p. 7-14). Because the transportation corridor for the PUDA stockpile contains a much lower population density than that experienced during the transport of the German stockpile, there is reason to believe that the measures of risk could be less for transporting the PUDA stockpile. In spite of a potentially lower health and safety risk associated with the transport of the PUDA stockpile relative to the experience in Germany, it is not currently possible to assess the merits of emergency planning and preparedness in reducing the risk of an accident or fatalities if an accident were to occur. The Army's conclusion that recent developments in emergency preparedness would not have altered the programmatic decision favoring on-site disposal is valid (U.S. Army 1993, p.7-14). 


\section{SITE-SPECIFIC EIS}

\subsection{METEOROLOGY}

\subsubsection{General}

The meteorology and air quality section of the site-specific EIS should evaluate impacts of routine operation of the Chemical Stockpile Disposal Program (along with construction impacts), as well as impacts to human populations from the accident scenarios.

Relative to routine operation, on-site meteorological data (if found to be valid, as mentioned above) should be used to evaluate compliance with air quality standards at the site boundary. Finally, the study should include the on-site population in the analysis of potential casualties of an accidental release.

\subsubsection{D2PC Model and Choice of Meteorological Conditions}

The D2PC model was used in the FPEIS for dispersion analyses to evaluate the consequences of the various off-site transportation and on-site accident scenarios at all eight stockpile sites. However, the D2PC model is applicable only to dispersion in reasonably flat terrain under simple meteorological conditions. The errors that arise in application of the model to a specific site depend strongly on how the assumptions in that model match the actual conditions at the site being studied. The EIS for each depot is supposed to assess the site-specific impacts of implementing the Chemical Stockpile Disposal Program at that site and evaluate possible alternative locations for the incineration facility within the depot.

Because of the gently rolling terrain present at the PUDA, the D2PC model can be applied to the site only if knowledge of the flow patterns by time of day is available. Such information is available only qualitatively. An experienced user of D2PC (with a meteorological background) armed with information on time-of-day variations in wind and pollutant motion could use D2PC in an effective way for conditions at the PUDA. A person with little meteorological experience or little or no knowledge of the possible plume motions would find it better to use a variable-terrain flow and dispersion model such as the MACH series of codes developed by the U.S. Army Atmospheric Sciences Laboratory at White Sands Missile Range, New Mexico. We recommend that the MACH codes (or a similar type of model) be run for selected nighttime ( $F$ stability) and daytime periods, and that plume predictions (concentrations and locations) be compared with the Phase I methodology (counting fatalities) using D2PC. If this exercise projects fewer fatalities by using a variable terrain model, it should provide some confidence in the D2PC modeling results as they were developed for the Phase I document. The question of zigzags in the plume direction possibly leading to additional fatalities unaccounted for in the Phase I methodology using D2PC could then be evaluated. The use of meteorological data from both the airport and the site would be appropriate in such an evaluation. 
The MACH codes are currently being considered for use in emergency response at the site. This course of action is advisable because of the complex patterns of flow and dispersion that could occur during an actual accident. Six additional meteorological towers are being planned to better estimate the wind field during an accident. However, we recommend that the MACH models should also be used in the site-specific EIS to evaluate worst-case conditions (as described above) and to verify the results obtained with D2PC.

Another important issue for the site-specific EIS relates to the meteorological conditions selected for the dispersion analysis (Section 3.1). The D,3 and E,1 conditions selected for use in the FPEIS analysis appear to have been subjective choices, and it is not certain that they represent conservative conditions for purposes of this impact assessment. Table 6.1 of the Phase I report presents the joint frequency distribution of stability and wind rose for the Pueblo Memorial Airport. These data indicate frequencies of $0.8 \%$ for Class A stability, $8.0 \%$ for Class B stability, $14.5 \%$ for Class C stability, $44.1 \%$ for Class D stability, $18.4 \%$ for Class E stability, and $14.2 \%$ for Class F stability. Neither that table nor the accompanying text (U.S. Army 1993) provides any substantive support for the D,3 and E,1 selections, which leads us to conclude that the choice of these particular meteorological conditions was subjective. Other meteorologists could reasonably make and defend other choices. We recommend that the Army consider remodeling dispersion characteristics with other reasonable stability and wind speed combinations (such as D,5 and E, 3 for conservativemost-likely and F, 1 and F, 3 for worst-case scenarios) and then compare the projected doses to the population for these other combinaiions. The Phase I report evaluated the $D, 1$ alternative but did not find greater impacts than the $D, 3$ choice. Other alternatives were not tested.

It is important to recognize that the meteorological scenarios selected are important only because they are needed to compute potential dosage values for the population near the PUDA. Depending on the relative location of the population with respect to the PUDA, the largest doses to the public may or may not result from the D, 3 and E,1 conditions. All reasonable possibilities need to be checked, not just D,3 and E,1.

Only through a sensitivity analysis with respect to wind speed and stability class can

the effect of the subjective choice of meteorological conditions be evaluated. These evaluations should be done in conjunction with the more important study of the effects of the complex meteorology on fatality projections, as described above. The impacts to on-site personnel should also be included in the dosage comparisons with the different stability class/wind speed combinations.

\subsection{POPULATION}

The Phase I report notes that on-post and special populations near the PUDA will be considered in the estimates of potential fatalities for the site-specific EIS. The use of these more detailed data is both valid and appropriate. It should also be acknowledged that the authors of the Phase I report did a thorough job of identifying the off-post resident and worker populations, transient populations, and special populations within a $100-\mathrm{km}$ radius 
of the site. Given that the risk calculations were based on exposures only to healthy adult males and the fact that some subgroups of the population (e.g., children up to 14 years old and adults 65 and older) are much more sensitive to chemical agents than healthy adult males, the new age-specific data for off-post populations should be used in the site-specific EIS to generate more accurate risk calculations.

\subsection{SOCIAL, ECONOMIC, AND CULTURAL RESOURCES}

Unlike the method used to conduct the population analysis, systematic methods or models were not used in the FPEIS and Phase I report to analyze data associated with social, economic, and cultural resources. For both the FPEIS and Phase I report, data were collected on public services/infrastructure and economic resources for the counties within a selected radius of the PUDA. However, even if the data collected for the Phase I report indicated that significant differences in impacts were expected compared with those projected in the FPEIS, this could not possibly alter the decision in favor of on-site disposal. The reason is that social, economic, and cultural resources were not explicitly used in the decision-making process.

We suggest that social, economic, and cultural resource issues (including environmental equity) be included explicitly in the decision-making process for the sitespecific EIS. The Phase I report does not address data requirements for social, economic, or cultural resource issues associated with the proposed construction of the water pipeline. The impacts associated with the proposed water pipeline require consultation with the State of Colorado Historic Preservation Office (SHPO). It is possible that the SHPO will require a survey for archaeological and cultural resources along the proposed construction and easement route.

\subsection{WATER RESOURCES}

As che Phase I report indicates, risks or impacts to surface water and groundwater resources were not considered in the FPEIS decision methodology. Therefore, it is not necessary to compare the data presented in the FPEIS and the Phase I report. Rather, the Phase I report presents site-specific information on surface water and groundwater that will be used in the site-specific EIS impact analysis for the PUDA. The site-specific data will be used to quantify the baseline environment, to map water resources that occur within the region of influence described in the FPEIS $(100 \mathrm{~km})$, and to provide information on initial conditions for analysis of surface and groundwater flow dynamics. These studies will provide the information needed to judge the site-specific human health and aquatic ecosystem risks associated with on-site disposal at the PUDA.

The surface water information presented in the Phase I report provides sufficient site-specific data on the Arkansas River, the major water resource in the region of influence, and on Chico, Boone, and Haynes creeks on the PUDA reservation. In addition, the Phase I report indicates the presence of an extensive storm-water drainage system to channel surface 
flow to the reservation creeks. Information on flow rates from the PUDA drainage network is not provided. Such information should be presented in the site-specific EIS. The public water intakes downstream of PUDA are listed, but we also recommend that the location of the nearest public water intake be provided in the EIS. However, the accident database indicates that the Arkansas River, the source of public water, is not at risk from the largest credible accidental release of a chemical agent.

No new information exists or was developed for the Phase I report relative to the presence of surface water that would affect the FPEIS decision for on-site disposal. However, the proposed location of the incinerator carries storm-water drainage from the chemical agent storage area to Haynes Creek. The EIS will have to determine facility construction and operation impacts on surface water quality and flow at this location. This information can be used to explicitly examine accident impacts on surface waters in Haynes Creek and Linda Ann Reservoir. Because the FPEIS decision methodology did not consider water resources, the impact analysis for the site-specific EIS will contribute new information to the implementation of on-site disposal at the PUDA. The proposed location for the disposal facility makes it unlikely that surface water outside the reservation boundaries would be impacted by the worst-case accident scenario. Groundwater information contained in Appendix $\mathrm{C}$ of the Phase I report provides sufficient detail for the affected environment section of the site-specific EIS. As stated in the Phase I report, an extensive well network provides all the water needs of the PUDA. The site-specific EIS should provide information on the location of the wells in relation to the agent storage areas and the proposed location for the agent disposal facility. On the basis of existing geologic conditions, the groundwater in the Arkansas River alluvium, an important source of regional water supply, is not connected to the groundwater in alluvial deposits beneath the PUDA. Thus, impacts to offreservation groundwater supplies are highly unlikely. While the proposed disposal facility is to be located on soils with rapid permeability, impacts to groundwater from a worst-case accident would be limited to the reservation.

Because groundwater is not present in sufficient quantities to meet the process needs of the disposal facility at the PUDA, a 16- to 24-km-long pipeline, with an intermediate pumping station, will have to be constructed to link with the city of Pueblo water supply. The site-specific EIS must examine the impacts of pipeline construction and operation. Explicit consideration should be given to how water allocations to the disposal facility could affect other water users or the water resource of the Pueblo Reservoir on the Arkansas River.

\subsection{ECOLOGICAL RESOURCES}

In the FPEIS, explicitly protected ecological resources were listed as being at risk from accidental releases of agent. However, these resources were not used to quantify ecosystem risk; the atmospheric dispersion model was used to measure ecosystem risk by defining the expected plume area around the PUDA disposal location. Implicit in this calculation is the assumption that the greater the plume area, the larger the impact to the surrounding biota. The calculation, and thus the subsequent index of risk, did not change 
during the Phase I analysis. Therefore, inclusion of all protected ecological resources in the Phase I report is only necessary to support impact analyses in the site-specific EIS.

The Phase I report identifies and maps the locations of all publicly owned land areas within $100 \mathrm{~km}$ of the PUDA that contain natural ecological systems. In addition, all threatened and endangered species are identified for inclusion in the EIS. Fu, ther information on threatened and endangered species has been requested from the U.S. Fish and Wildlife Service. For major natural areas and important habitat for threatened and endangered species, that information adequately defines the baseline environment in the PUDA region. Impact analyses of these ecological resources conducted for the site-specific EIS would serve as an acceptable index of potential impacts to biological and ecological resources within the entire $100-\mathrm{km}$ area surrounding the PUDA.

The Phase I report provides limited data on terrestrial or aquatic biota at the PUDA installation properties. Locational information on ecological resources is essential for completion of the site-specific EIS. For example, information on the locations of plant communities and animal habitats is needed to judge the impacts of road construction. It is recommended that ecological data from the installation be presented in the site-specific EIS and that this information be used in the impact analysis of disposal facility construction and operation.

The Phase I report considers the proposed construction of the water pipeline from the city of Pueblo to the disposal facility at the PUDA in the reanalysis of the ecological data. The pipeline construction and easement route will require a survey for threatened and endangered species and consultation with the U.S. Fish and Wildlife Service. Because threatened and endangered plant populations are known to occur in the region and because the U.S. Army and the U.S. Fish and Wildlife Service are cooperating in the black-footed ferret program at the PUDA, the location of the pipeline will depend on the outcome of field surveys.

\subsection{EMERGENCY PLANNING AND PREPAREDNESS}

For emergency planning, the U.S. Army is currently considering the use of D2PC and other computer codes (including the High Order Turbulence Model for Atmospheric Circulation/Random Particle Transport and Diffusion [HOTMAC/RAPTAD] of Los Alamos National Laboratory and the MACH codes of the Atmospheric Sciences Laboratory, White Sands Missile Range) in an emergency preparedness model for the PUDA. This type of modeling plan is appropriate, and it should be recognized that the individuals responsible for executing the codes in an emergency (daytime or nighttime) should have sufficient training and experience in meteorology to be able to properly use the models under a variety of conditions. 


\section{CONCLUSIONS}

Applying only the decision methodology used by the U.S. Army in the FPEIS and Phase I report with respect to the updated population estimates produces no significant differences between the information presented in the FPEIS and that presented in the Phase I report for the PUDA. The projected number of people exposed to accidental releases of chemical agents was found in the Phase I report to be larger (by 10,185 people) than that contained in the FPEIS. As a result, the number of expected fatalities under worst-case conditions increased from 16,500 in the FPEIS to 16,800 in the Phase I report. The FPEIS methodology required an increase that exceeded some number larger than 16,000 (or a 100 -fold increase in the other measures of risk) to be considered sufficiently significant to reject on-site disposal. Other than changes in estimates of the size and distribution of the human population, no other data were altered in the Phase I report.

The Phase I report adequately describes the current environmental conditions at the PUDA and the surrounding region. The information contained in the Phase I report adequately addresses surface water and groundwater attributes needed to analyze impacts to water users and aquatic biota.

Under the FPEIS and Phase I process, only one proposed disposal location has been considered for the PUDA. Although this site location has been subject to preliminary engineering analyses, the U.S. Army, in the site-specific EIS process, is committed to evaluating other on-site locations if environmental impacts at the initially proposed site are of a magnitude to warrant facility relocation. If other locations are considered in the EIS, the FPEIS risk measures will have to be recomputed. The determination of whether changes in the risk measures that result from these recomputations are significant will also be based on subjective criteria for significance that are formulated by the U.S. Army. 


\section{REFERENCES}

Krummel, J.R., et al., 1988, Chemical Stockpile Disposal Program: Review and Comment on the Phase I Environmental Report for the Tooele Army Depot, Tooele, Utah, ANL/EES-TM-359, Argonne National Laboratory, Argonne, Ill.

Krummel, J.R., et al., 1989, Chemical Stockpile Disposal Program: Review and Comment on the Phase I Environmental Report for Anniston Army Depot, Anniston, Alabama, ANL/EAIS/TM-5, Argonne National Laboratory, Argonne, Ill.

Krummel, J.R., et al., 1990a, Chemical Stockpile Disposal Program: Review and Comment on the Phase I Environmental Report for the Umatilla Depot Activity, Hermiston, Oregon, ANL/EAIS/TM-33, Argonne National Laboratory, Argonne, Ill.

Krummel, J.R., 1990b, Chemical Stockpile Disposal Program: Review and Comment on the Phase I Environmental Report for the Pine Bluff Arsenal, Pine Bluff, Arkansas, ANL/EAIS/TM-34, Argonne National Laboratory, Argonne, Ill.

National Academy of Sciences, 1991, Workshop on the Pollution Abatement System of the Chemical Agent Demilitarization System, Committee on Review and Evaluation of the Army Chemical Stockpile Disposal Program, National Research Council, Washington, D.C., May 15-17.

National Academy of Sciences, 1992, Review of the Choice and Status of Incineration for Destruction of the Chemical Stockpile, Letter Report of the Committee on Review and Evaluation of the Army Chemical Stockpile Disposal Program, National Research Council, Washington, D.C., June 15.

Steranka, P., 1993, Meteorological Monitoring at Pueblo Depot Activity, Memorandum from Steranka (Industrial Risk Management Division, Pueblo Depot Activity, Pueblo, Colo.) to K. Miller (U.S. Army Chemical Munitions Destruction Agency, Aberdeen Proving Ground, Md.), Nov. 30.

U.S. Army, 1988a, Chemical Stockpile Disposal Program Final Programmatic Environmental Impact Statement, Vols. 1-3, Program Executive Officer - Program Manager for Chemical Demilitarization, Aberdeen Proving Ground, Md.

U.S. Army, 1988b, Chemical Stockpile Disposal Program Implementation Plan, Report to Congress on March 15, 1988, Program Executive Officer - Program Manager for Chemical Demilitarization, Aberdeen Proving Ground, Md.

U.S. Army 1988c, Chemical Stockpile Disposal Program Phase I Environmental Report for

Tooele Army Depot, Tooele, Utah, Program Executive Officer - Program Manager for Demilitarization, Aberdeen Proving Ground, Md. 
U.S. Army, 1988d, "Record of Decision: Chemical Stockpile Disposal Program," Federal Register 53(38):5816-5817, Washington, D.C., Feb. 26.

U.S. Army, 1993, Disposal of Chemical Agents and Munitions at Pueblo Depot Activity, Final Draft of Phase I Environmental Report, Program Executive Officer -Program Manager for Chemical Demilitarization, Aberdeen Proving Ground, Md.

Williams, M.D., et al., 1987, Chemical Downwind Hazard Modeling Study: Evaluation of Model Concepts and Site Assessment, LA-UR-87-897, Los Alamos National Laboratory, Los Alamos, N.M. 

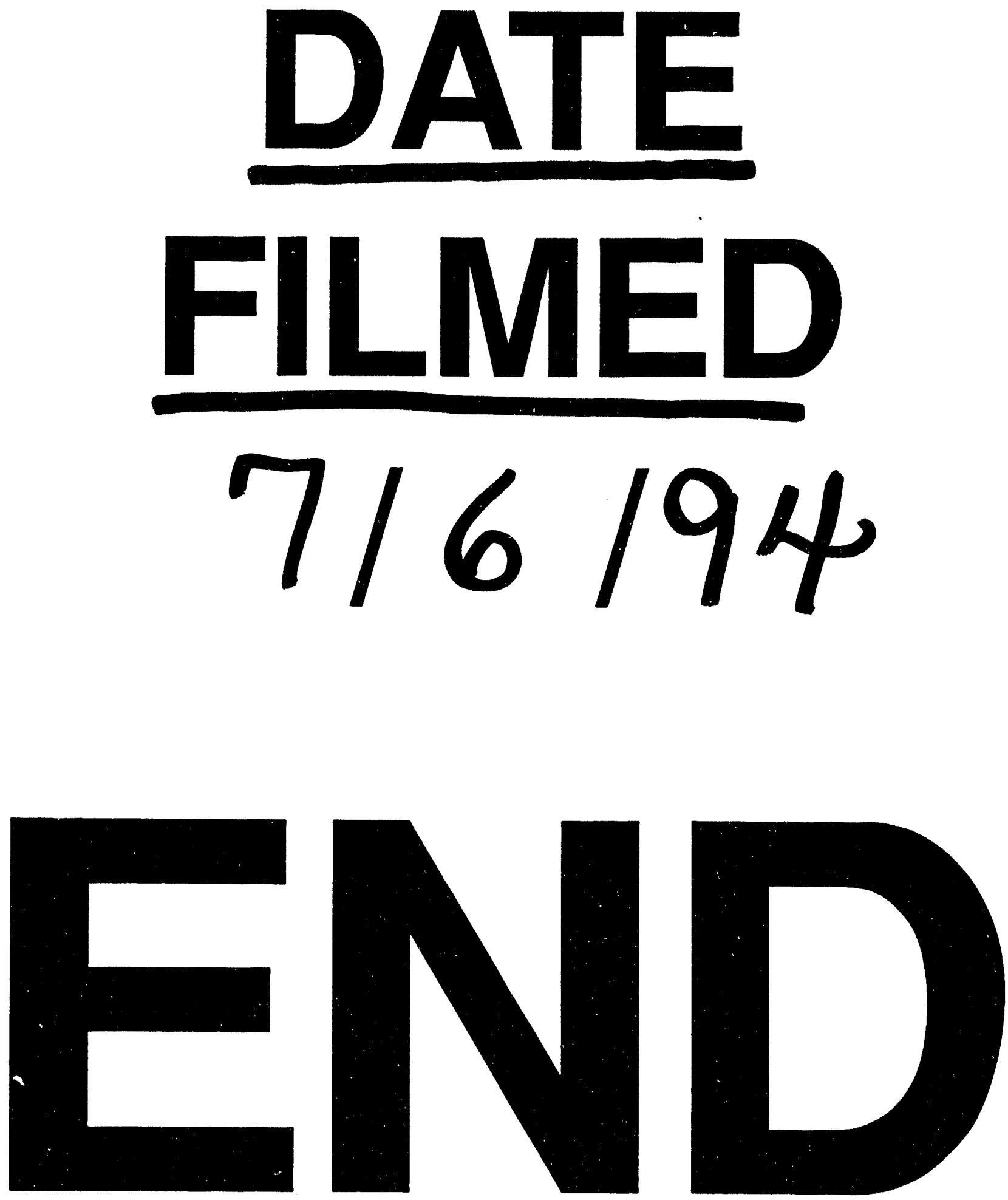